\title{
DOCÊNCIA EM AMBIENTE DIGITAL IMERSIVO: NA PERSPECTIVA DO PROFESSOR
}

\author{
Marcelo Pedroso da Roza - PPGE, IFFarroupilha/UFSM, mroza@iffarroupilha.edu.br \\ Adriana Moreira da Rocha Veiga - PPGE, UFSM, adrianaufsm@gmail.com \\ Jiani Cardoso da Roza - PPGE, IFFarroupilha/UFSM, jiani.cardoso@gmail.com
}

\begin{abstract}
Resumo. Este artigo aborda os caminhos da docência em Ambiente Digital Imersivo (ADI) tendo como objetivo principal analisar de que modo se constituem os processos de auto(trans)formação docente na aprendizagem da docência virtual mediada por ADI. Com enfoque qualitativo, foi realizada uma experiência em sala de aula, em Imersão com a utilização do OpenSim. Neste experimento os professores foram encorajados a aplicar um mix de metodologias composto pela Investigação Formação de Maciel (2015) e os Círculos Dialógicos Investigativo Formativos proposto Henz (2015). Deste modo, essa pesquisa contribui no sentido de: mostrar que o processo de auto(trans)formação docente também se estabelece em um ADI ao determinar quais elementos constituem a ambiência pedagógica no mundo digital imersivo, gerar discussões em torno de como o professor efetiva a relação entre os saberes pedagógicos e tecnológicos na ambiência pedagógica digital e relatar as experiências vivenciadas pelos professores em situação de ensino/aprendizagem na ambiência pedagógica digital. Como resultados destacamos: a consolidação de uma metodologia hibrida denominada como Mash Investigativo Formativo e a trajetória de auto(trans)formação dos docentes envolvidos.
\end{abstract}

Palavras-chave: Ambiência Imersiva Educacional, Formação Docente, Ensino Imersivo

\section{TEACHING IN IMMERSIVE DIGITAL ENVIRONMENT: IN THE TEACHER'S PERSPECTIVE}

\begin{abstract}
This paper discusses the ways of teaching in Immersive Digital Environment (IDE) with the main objective of analyzing how the processes of teacher self (trans) formation in the learning of virtual teaching mediated by IDE are constituted. With a qualitative focus, a classroom experiment was carried out, in Immersion with the use of OpenSim. In this experiment the teachers were encouraged to apply a mix of methodologies composed by the Maciel Training Research (2015) and the Dialogic Research and Training Circles proposed by Henz (2015). Thus, this research contributes to: show that the process of teacher self (trans) formation is also established in an IDE in determining what elements constitute the pedagogical environment in the immersive digital world, generate discussions about how the effective teacher relationship between pedagogical and technological knowledge in the digital pedagogical environment and to report the experiences of teachers in a teaching / learning situation in the digital pedagogical environment. As results we highlight: the consolidation of a hybrid methodology called Mash Investigative Formative and the trajectory of self (trans) formation of the teachersinvolved.
\end{abstract}

Keywords. Immersive Educational Environment, Teacher Training, Immersive Teaching

\section{Introdução}

Para viver, aprender e trabalhar bem em uma sociedade cada vez mais complexa, rica em informação e baseada em conhecimento, os alunos e professores devem usar a tecnologia de forma efetiva, pois em um ambiente educacional qualificado, a tecnologia pode permitir que os alunos se tornem: usuários qualificados das tecnologias da 
informação; pessoas que buscam, analisam e avaliam a informação; solucionadores de problemas e tomadores de decisões; usuários criativos e efetivos de ferramentas de produtividade; comunicadores, colaboradores, editores e produtores; cidadãos informados, responsáveis e que oferecem contribuições (UNESCO, 2009a).

Em 2004, O'Reilly (2006) cunhou o nome web 2.0 para uma nova forma de interação pela Internet, onde o "2.0" indica uma nova versão da Internet, um novo capítulo, novos rumos para a grande rede. O objetivo é fornecer aos navegantes mais criatividade, compartilhamento de informação e, mais que tudo, colaboração entre eles, fazendo com que esses navegantes tomem parte nesta revolução, salientando ser essa novidade muito mais do que uma nova cara para velhos aplicativos. Uma das possibilidades criadas pela web 2.0 é a de utilizar a Realidade Virtual como um recurso acessível, por Realidade Virtual entendemos que é uma técnica de interface avançada, através da qual o usuário movimenta-se interagindo com o ambiente tridimensional em tempo real, podendo fazer uso de dispositivos multissensoriais (Fagundes, 2010).

Embora os mundos virtuais apresentem uma série de características que, quando efetivamente exploradas, tendem a oferecer ao docente uma poderosa ferramenta para a educação, ainda hoje a complexidade de tais recursos tem sido vista por eles como um possível empecilho para a sua adoção em suas práticas educacionais.

Nesta linha, investigar estratégias de ensino, ao que podemos também agregar o conceito de coreografias de ensino ou coreografias didáticas (Zabalza, 2006) e testar possibilidades metodológicas no uso de ambientes imersivos para educação é um novo objeto de estudo. Em face disso, esta pesquisa buscou investigar a docência exercida dos Ambientes Digitais Imersivos com vistas a mapear os procedimentos metodológicos necessários para constituir uma ambiência docente e avaliar sua utilização dentro deste conceito de virtualização da aprendizagem.

\section{A docência em Ambiente Digital Imersivo}

Entende-se que a apropriação das TIC como tecnologias cognitivas depende do compromisso e da capacidade auto transformativa do professor mediante o enfrentamento dos desafios cognitivos e atitudinais. Vivenciando em si as mudanças cognitivas terá a compreensão necessária para mediar os seus estudantes na direção de construções cognitivas mediadas pelas TIC, preparando estes para a autogestão do conhecimento (Pellanda, 2009).

Em termos pedagógicos, as tecnologias deveriam ser projetadas para que qualquer professor pudesse modificá-las e adaptar seus materiais a elas, intencionando com isso atender melhor seus estudantes e currículos, permitindo uma grande gama de flexibilidade ao que seria antes visto em uma sala de aula tradicional. Uma das adaptações mais prementes no ensino-aprendizado integrado às tecnologias digitais será a do papel do professor que se tornará agente de facilitação na utilização da informação disponível e instruirá nos cuidados necessários quando buscamos por informações, pois para Levy (2014), qualquer pessoa pode, em seu próprio idioma, se comunicar com qualquer outra, sem se preocupar em conhecer o idioma de destino da mensagem, isso tornará a comunicação muito mais simples e suscetível a perigos e enganos, reforçando o papel de mediador do professor.

A geração atual de estudantes já é familiarizada com a tecnologia digital. Boa parte dos professores também utilizam as TIC em seu cotidiano, porém poucos utilizam em sala de aula como ferramenta didática ou recurso pedagógico. Nos espaços acadêmicos a TIC ainda soa como instrumento da pós-modernidade, excêntrico e fluido, com fim em si mesmo. Desta forma, há a necessidade de uma mudança de concepção do uso das tecnologias de informação e comunicação de modo a compreender que a cultura 
da convergência digital e tecnológica representa uma transformação cultural na qual os envolvidos querem participar ativamente da produção e da seleção dos conteúdos, da escolha, das decisões, por meio de interações mais dinâmicas, complexas e universais. E desta forma, as instituições de ensino e a docência também necessitam apropriar-se dessa cultura digital, na qual já é descabido ignorá-la. Os mundos virtuais imersivos são apenas uma das possibilidades de aplicação das TIC na educação. Cabe as instituições de ensino e professores conhecer e se apropriar dessas possibilidades, criando-se assim uma ambiência docente, tal como a "ambiência imersiva educacional".

\section{Metodologia}

Essa experiência tratou de captar e compreender o itinerário na ambiência docente em Ambientes Imersivos com utilização da Investigação Formação de Da Rocha (2006) e os Círculos Dialógicos Auto(trans)formativos, propostos em Henz (2015), a partir das semelhanças que tornaram as duas investigações consoantes e articuláveis, ambas têm por objetivo obter uma formação docente mais qualificada e consciente. Dessa forma, com base nas espirais representativas dos dois métodos, este trabalho utilizou a articulação de ambas.

Com base nessa articulação foi elaborada a proposta de um modelo, um Mash (MIF - Mash Investigativo Formativo), que une a investigação Formação e os Círculos Dialógicos Investigativo Formativos de Da Rocha (2006) e Henz (2015), respectivamente, vide Figura 1.

Figura 1: Mashup Investigativo Formativo

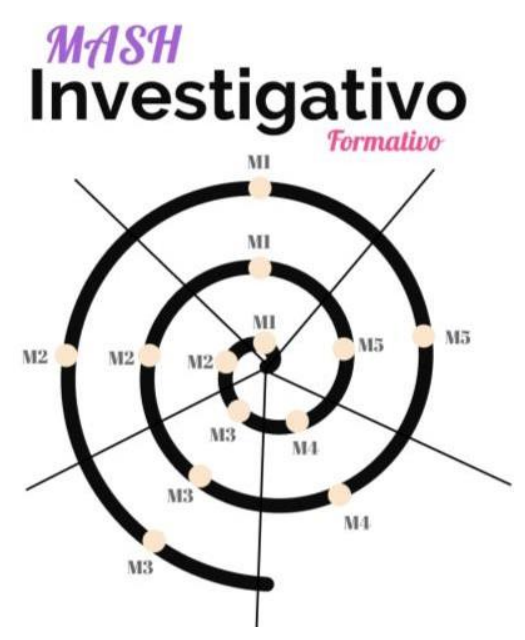

Fonte: autor

Onde M1 representa a etapa de sensibilização onde foi feita uma reunião com os sujeitos do estudo e foram apresentadas as pretensões da pesquisa (objetivos gerais e específicos) e a sistemática com a qual foi trabalhada no período da experiência. M2 é a etapa de Ações de Formação para Auto(trans)Formação onde foi realizado o planejamento das atividades dos professores, foi apresentado o ambiente imersivo junto com oficinas de aprendizagem e, com isso, levar os professores a perceber seu inacabamento como ser humano e que, como tal, está em permanente processo de auto(trans)formação. M3 é a etapa de Imersão Dialógica onde foram realizados encontros com os sujeitos da pesquisa com o objetivo de identificar os motivos pelos quais se dá a percepção/não percepção de seu inacabamento, para então elaborar um projeto de aprendizagem sob essa nova perspectiva realizando a troca de experiências vivenciadas pelos professores. M4 chamada de Diálogos Processuais, nesse momento serão realizados 
encontros onde todo o processo será revisto, repensado, novos questionamentos levantados, relatos de experiências descritos, boas/nem tão boas práticas descritas podendo levar a uma reescrita de todo o processo. Finalmente M5 ou Reconfiguração onde os sujeitos do estudo se conscientizam da realidade e se engajam plenamente na busca por uma transformação e, com isso modificam/não modificam suas práticas com o emprego da tecnologia imersiva.

Este estudo contou com a participação de três professores atuantes em Cursos Superiores de Tecnologia do IFFarroupilha, a saber: Licenciatura em Química, Análise e Desenvolvimento de Sistemas e Técnico em Informática. Estes professores têm formação inicial proveniente de curso superior de tecnologia, bacharelado ou licenciatura, atuam a pelo menos 2 anos na instituição nestes cursos e não mais de oito anos e são representados no experimento como professor $\mathrm{A}$, professor $\mathrm{B}$ e professor $\mathrm{C}$.

Para maiores detalhes quanto as especificações do MIF, os dados completos estão apresentados em (Da Roza, 2017).

\section{Experiência vivenciada pelos professores em situação de ensino/aprendizagem na ambiência pedagógica digital}

As atividades dos experimentos foram realizadas com o auxílio de três professores que atuam em cursos do Instituto Federal Farroupilha Campus de Alegrete, foram selecionadas uma turma da disciplina de Montagem e Manutenção de Microcomputadores do Curso Técnico em Informática Subsequente com o Professor A, uma turma da disciplina de Fundamentos da Informática do curso de Licenciatura em Química com o Professor B e uma turma de Programação I do Curso Superior de Tecnologia em Processamento de Dados com o Professor C, totalizando 20, 20 e 10 estudantes respectivamente. Os professores A, B e C tinham bom conhecimento na utilização de computadores e os estudantes apresentavam diferentes níveis de conhecimento dos recursos de informática. Os trechos transcritos a seguir foram escolhidos por representar algumas das situações significativas que os docentes se depararam no transcorrer do semestre onde optaram por tentar aplicar a tecnologia.

$\mathrm{O}$ professor $\mathrm{A}$, apesar de seu bom conhecimento de informática, à primeira vista achou que não seria possível a utilização do ADI em sua disciplina (etapa M1):

“...Olha, eu dou aula de montagem e manutenção de microcomputadores, não vejo como utilizar isso em minha aula...Até penso que se fosse possível construir um computador virtual dentro do ambiente seria de muita utilidade, mas acho que não é possível essa construção com tão pouco tempo e tendo ainda que aprender a utilizar a ferramenta...” (Professor A).

O professor B achou que a experiência com seus alunos seria muito "legal":

“...Meus alunos vão adorar essa novidade, o que acontece hoje é a utilização do computador como um substituto do quadro branco e da caneta, vai ser algo diferente que, acredito eu, eles vão gostar muito." (Professor B)

Já o professor $\mathrm{C}$ se mostrou o mais empolgado com a possibilidade:

“...Que máximo isso, eu dei uma olhada no ambiente e vi as possibilidades que isso pode proporcionar e vai me ajudar muito, pois em minha disciplina de programação estou tentando iniciar a programação em três dimensões e esse ambiente vai ajudar muito minha aula." (Professor C)

Esse primeiro contato com o ambiente mostrou os perfis diferentes dos docentes, onde os professores A e B aceitaram fazer parte do experimento apesar de seus receios iniciais: 
“..., eu não sei se vou conseguir utilizar em minha aula, mas quero muito tentar usar... achei meio complicadinha a configuração e o uso disso, mas vamos lá" (Professor B). “...Olha ainda não imaginei uma utilização para isso em minhas aulas e estou chegando a conclusão que não sei nada de informática...” (Professor A).

Já o Professor C em seu primeiro contato, partiu logo para as tentativas de utilização e já manifestou intenção de colocar uso já em sua próxima aula:

“...muito legal esse ambiente, vou fazer uma cópia dele e repassar imediatamente para meu bolsista ir estudando e se preparando para ajudar os colegas no uso do ADI nas aulas de programação ... Será que posso enviar o material que nos deste para ele?..." (Professor C)

Os professores A e B relataram que seus estudos do ambiente se limitaram aos momentos em que o pesquisador esteve junto a eles presencialmente para prestar auxílio para suas descobertas:

“...Não tive muito tempo de estudar o ambiente em casa, quando estou em casa, minha filha exige muito minha atenção o que faz com que esse tipo de atividade fique restrita ao Instituto e aqui tenho que dividir meu tempo com minhas outras atividades, como preparar aula e atendimento a alunos bolsistas e outros que nos procuram...'(Professor B).

O Professor $\mathrm{C}$ trouxe um problema técnico que precisou da interferência do pesquisador junto ao Centro de Processamento de Dados do Campus, pois ao passar o ambiente ao seu bolsista, ele somente poderia utilizar o ambiente diretamente no laboratório de informática do Campus e ao tentar, percebeu que haviam bloqueios na rede que limitavam o tráfego de dados, o que não permitia o acesso ao ambiente. Ao contatar o pessoal técnico do Campus foi constatada a inexistência de bloqueios na rede, fato que nos levou a constatar que o problema seria na instalação do ambiente no computador do laboratório; em visita aos laboratórios do Campus foram constatadas falhas na instalação do ambiente, as quais foram sanadas e o ambiente passou a ficar acessível. Por motivos de segurança, o ambiente ficou sem acesso externo ao campus, ou seja, tanto estudantes quanto professores, somente poderiam acessar o ambiente de dentro do laboratório onde ele está instalado.

“...Uma pena que os alunos não podem acessar o ambiente de casa, pois o tempo que eles têm em sala de aula, não é suficiente para que eles possam se desenvolver muito naquela ferramenta ...” (Professor C)

Ao fazer essa manifestação o professor evidenciou a intenção de que seus alunos pudessem acessar a ferramenta de casa para aprimorar seus estudos da ferramenta. A partir dessa intenção foi repassado ao professor que ele poderia fornecer uma cópia do ambiente para cada aluno, pois ele é um ambiente do tipo opensource-freeware, ou seja, tem o código aberto para quem quiser e souber modificar sua estrutura interna e também é de distribuição livre, não dispendendo custos para sua distribuição aos alunos.

Em um dos encontros virtuais com os docentes foi feita uma pergunta sobre as limitações no uso da tecnologia que eles julgavam mais relevante:

\footnotetext{
"Vejo que uma das limitações para o uso das TICs está na falta de uma formação do quadro docente na área de tecnologia. Um docente inseguro não terá condições de desenvolver um bom trabalho. Mas não basta somente a formação, o docente deve estar consciente de que o uso das TICs é necessário, pois isso já faz parte do dia-a-dia dos discentes. Negar essa realidade é estacionar no tempo e acomodar-se." (Professor B)

“...A pouca participação do corpo docente no uso da tecnologia é uma limitação. O Instituto fornece laboratórios, acesso a Internet e recursos para que a tecnologia seja bastante utilizada, mas o que vemos não é isso, o que vemos é professores dando aula em uma sala tradicional com o uso do datashow para
} 
mostrar slides do powerpoint em vez de escrever no quadro branco..." (Professor A).

Dentro desse período houveram algumas tentativas de utilização do ambiente em sala de aula, o Professor A relata que foi difícil a utilização a primeira vista, pois ele não fez uma preparação para essa primeira aula, sua intenção foi a de fazer o cadastro dos usuários e que eles pudessem ver o ambiente e o ajudassem a dar uma forma para o mundo virtual:

“Em princípio não planejei uma atividade dentro do ambiente, minha intenção foi levar a novidade para a aula e com eles buscar alternativas para o uso do ambiente em sala de aula. Como minhas aulas são separadas de dois em dois períodos, descobri que dois períodos é pouco tempo para realizar o cadastro dos alunos. Eles criam senhas e esquecem, criam nomes de usuários e não anotam, problemas de comunicação com o servidor e problemas com o viewer foram alguns dos problemas que aconteceram e deixaram as coisas bem demoradas." (Professor A).

Na realidade, todos os professores tiveram problemas desse tipo, o que não deixa de ser normal para a utilização de uma nova tecnologia, em outra época, nós mesmos já tivemos problemas desse tipo quando foi inserida em uma experiência de sala de aula, uma turma de Seminário de Tese II do PPGE da UFSM em um ambiente virtual. Os problemas e a sensação foram as mesmas e o tempo para partilhar dessa novidade foi reduzido, mas foi suficiente para que meus colegas experimentassem o mundo Imersivo.

Durante as pesquisas para melhor compreender o ambiente o Professor $\mathrm{C}$ descobriu que era possível ter interação por voz no ambiente, a partir daí ela solicitou ao seu bolsista que tentasse liberar esse recurso no ambiente que ela havia repassado a ele:

“Oi, descobri que é possível ter chat por voz dentro do ambiente, pedi ao meu bolsista que tentasse instalar esse módulo no nosso ambiente, mas ele não conseguiu fazer isso. Podes nos ajudar?" (Professor C)

O Professor C saiu frustrado ao descobrir, por mim, que não seria possível instalar o módulo de voz devido ao fato de existirem dois tipos de instalação do OpenSim: standalone que é a instalação mais simples que permite sua utilização em pequenas redes ou apenas no próprio computador e a servidora que é uma instalação para servidores abertos que disponibilizariam seus serviços na rede (Internet). A instalação escolhida para este experimento foi a standalone devido a sua simplicidade na instalação, essa escolha teve um preço, nem todos os serviços estão disponíveis para ela e o chat por voz é uma dessas indisponibilidades. Instalar a versão de servidor iria demandar autorização de acessos aos servidores do campus, ou a montagem de um servidor separado para ficar disponível no CPD do Instituto, o que fugiria do escopo desse projeto, dessa forma o professor ficou sem o chat por voz. Já o pesquisador sentiu que aquele professor foi além do esperado e em suas buscas por conhecer mais sobre as possibilidades do ambiente descobriu novas possibilidades que gostaria de implementar com seus alunos.

O Professor A relatou que após a tentativa inicial onde fez o cadastro dos usuários ele deixou de lado o ambiente e prosseguiu suas aulas da forma tradicional por acreditar não ter como utilizar o ambiente para aquela disciplina:

"Eu gostei da ideia de utilizar um recurso desses como ferramenta de ensino, mas acho que não vou conseguir utilizar o ambiente nas minhas aulas, eu leio sobre o assunto e vejo que existem algumas possibilidades, mas a maioria delas está ligada a grupos de pesquisa onde são muitas pessoas para desenvolver recursos e funcionalidades, acho que não tenho condições de em tão pouco tempo desenvolver algo igual." (Professor A).

Apesar desse aparente descrédito do professor, ele aceitou tentar novamente com os alunos a utilização do ambiente, mas dessa vez como uma iniciativa dos próprios alunos: 
"E não é que os alunos querem tentar mais um pouco, como a iniciativa partiu deles, propus então que eles trouxessem sugestões de como utilizar a ferramenta na aula. Eles quiseram construir um ambiente independente da disciplina, apenas para praticar um pouco e ter uma atividade diferente. Aceitei e eles construíram uma estrutura, não tinha muito haver com a disciplina, mas foi interessante vê-los empolgados por uma atividade dessas." (Professor A).

O Professor $\mathrm{C}$ foi o único que tentou trabalhar a estrutura do ambiente, como sua disciplina era Programação de Computadores ele tentou criar objetos e programar comportamentos nos objetos:

"Eu já tinha a intenção de tentar programar em três dimensões com meus alunos, tinha começado a estudar o scratch para essa finalidade, só o que tive que fazer foi mudar de versão da linguagem de programação, mudei para o scratch for OpenSim e percebi que é uma opção viável para meus alunos." (Professor C).

Com essa intenção o Professor $\mathrm{C}$ comentou ter encontrado muito material sobre essa programação em canais de desenvolvimento de software do youtube:

"No youtube encontrei bastante material sobre programação em scratch para OpenSim, repassei ao meu bolsista para que ele pudesse começar a fazer experiências e se apropriar dessa novidade. Acredito que os alunos devem gostar dessa possibilidade, pois o ambiente vai dar a eles a oportunidade de ver suas criações funcionando." (Professor C).

O Professor B também pensou em buscar na Internet opções para utilização do ambiente:

"Em minhas buscas para utilizar o ambiente achei vários laboratórios digitais de
química disponíveis na Internet, daí ao invés de utilizar o ambiente OpenSim,
optei por apresentar e utilizar alguns dos laboratórios prontos disponíveis na
Internet, um deles em OpenSim, dessa forma achei que utilizando esse recurso
já pronto teríamos uma experiência de imersão da mesma forma, com a diferença
de que eu não precisaria criar um laboratório com os alunos partindo do zero e
poderia reutilizar algo já desenvolvido e que tem a mesma finalidade minha."
(Professor B)

De uma forma ou de outra, os estudantes apreciaram a experiência de utilizar um ambiente imersivo.

A seguir algumas imagens da experiência:

Figura 2: Professor A - Com sua turma em laboratório

Fonte: Professor A

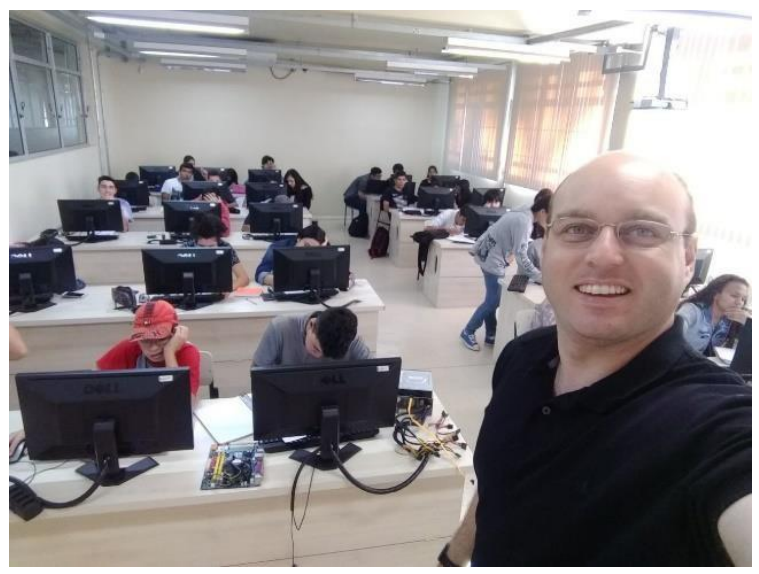

Na figura 2 o Professor $\mathrm{C}$ deixou os alunos tentarem criar sua estrutura no ambiente, eles seguiram um tutorial encontrado na Internet e construíram uma casa seguindo os passos desse tutorial. 
Figura 3: Programação no OpenSim com Scratch

Fonte: Professor C

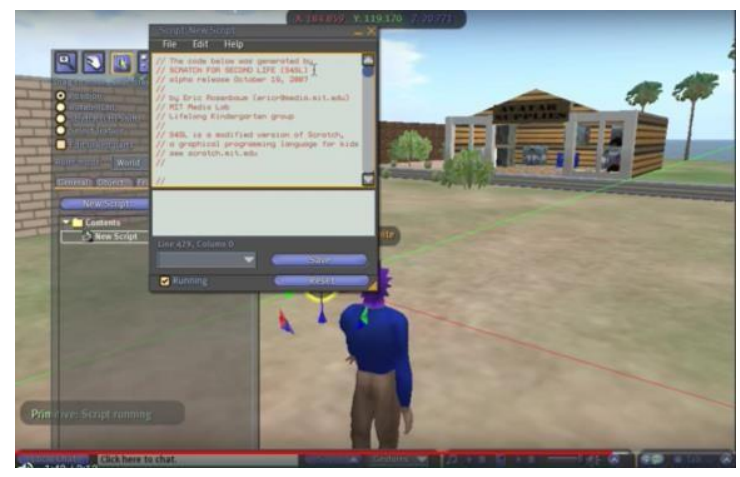

Desta forma, os Professores A, B e C passaram pelas etapas de preparação e aplicação do ADI com seus alunos, a experiência deles com o ambiente foi trabalhosa, mas compensadora e ao perguntar se eles poderiam continuar utilizando ADI como uma ferramenta de ensino em suas aulas:

\footnotetext{
"Sim, porque estimula a criatividade dos alunos, além de ter um papel importante na aprendizagem.” (Professor B)

"Sinceramente, acredito que não e não porque os alunos não tenham gostado, mas porque eu não me senti a vontade com ele." (Professor A)

"Sim, já estou pensando minhas aulas para a próxima turma usando diretamente o ambiente, quero me apropriar mais do seu funcionamento, aprender mais sobre ele e vou usar sim com certeza." (Professor C)
}

Os professores buscaram alternativas de como utilizar esse recurso em sala de aula. O Professor A de forma colaborativa com seus alunos, o Professor B encontrando alternativas e utilizando a mesma tecnologia sem passar pelo processo de configuração e aprendizado do ambiente propriamente dito e o Professor $\mathrm{C}$ com seu conhecimento de scratch aproveitou para adaptar o ambiente que se apresentou para programar objetos dentro de um mundo em três dimensões, dessa forma eles iniciaram o processo de apropriação da tecnologia.

\section{Considerações finais}

Pode-se dizer que um processo de Auto(trans)Formação docente começou no momento em que os professores aceitaram participar dessa experiência, pois visto como um processo contínuo que se desenvolve ao longo de toda a vida profissional a Auto(trans)Formação começa já na discussão de métodos para a utilização de inovação em sala de aula, somente esse ato já implica em modificação de práticas ainda que isso seja representado pela simples mudança no local da aula tradicional, que migraria de uma sala de aula para um laboratório de informática, deve ser notado que o ADI não representa uma simples mudança no ambiente de ensino, mas sim uma mudança completa na forma de ensinar visto que todo o ambiente deve ser montado para aquela situação e essa mudança pode começar principalmente pelo local onde professores e alunos podem ter acesso as tecnologias imersivas.

Com base nas observações e relatos de algumas situações docentes foi possível constatar que o MIF representou uma sugestão viável para estabelecimento de procedimentos metodológicos para utilização em Ambientes Digitais Imersivos. A proposta, por não ser uma estrutura engessada e fixa em suas etapas, foi utilizada nesse experimento mostrando que ela se trata de uma proposta baseada no diálogo, treinamento 
e retreinamento, reflexão sobre suas práticas e reconhecimento de suas possibilidades e limitações.

Neste estudo também foi possível esboçar um caminho no qual os professores podem percorrer para buscar a implementação de procedimentos metodológicos em um ADI, onde para isso foi proposto um método que uniu duas propostas metodológicas resultando em um Mash das duas para a criação de uma terceira derivada da articulação das principais características de ambas e assim descrever e implementar passos bem definidos para essa finalidade.

Com a observação e a escuta das situações vividas pelos professores pode-se constatar que nesse território tecnológico o professor tem que ter a disposição para falhar, ele deve estar ciente de que nem tudo o que foi planejado funcionará daquela forma, vista a experiência do Professor A que acreditava que iria fazer uma breve experiência com os alunos, mas suscitados por eles retomou a utilização do ambiente.

Como se trata de uma novidade, muito deve ser estudado quanto as transformações necessárias ao processo de formação docente, o processo de auto(trans)formação se torna fundamental, principalmente devido ao fato de que a tecnologia que devia ser mais propensa a inclusão acaba se tornando excludente se ignorada, pois os estudantes já estão imersos nas novas tecnologias tanto em casa quanto em seus aparelhos de telefone celular.

Com base nos achados de pesquisa também é possível inferir que professores que não experimentaram, em sua formação seja ela inicial ou continuada, o uso das Tecnologias Digitais em sua aplicação pedagógica, dificilmente conseguirão utilizar por eles mesmos esse recurso em sala de aula. Uma sugestão para uma formação que possibilite ao docente vivenciar essas "maravilhas" surgidas pela inclusão das tecnologias digitais como recurso pedagógico, seria a formação docente dentro do paradigma do ensino híbrido, ensino híbrido esse definido por Christensen, Horn e Staker (2013), com base nos estudos de Graham (2006), como sendo um modelo formal e inovador de educação.

Enxergamos que para um futuro seja necessário testar o MIF em outros domínios com outros sujeitos, quem sabe as contribuições que eles trariam para esse estudo? Outras Instituições de Ensino poderiam ser observadas para consolidar as características dos agentes de uma Ambiência Digital Imersiva. Novos saberes para novos domínios? Essas são questões que devem ser trabalhadas com a finalidade de consolidar os achados dessa pesquisa. Com o objetivo de ampliar as possibilidades de comunicação entre professor e estudantes, cursos de formação em tecnologias digitais deveriam ser promovidos e por fim estudar a utilização do MIF com outras tecnologias emergentes como a realidade aumentada, robótica, entre outras.

\section{Referências}

CHRISTENSEN, Clayton; M.; Horn, Michael. B.; Staker, Heather. Ensino híbrido: uma inovação disruptiva? uma introdução à teoria dos híbridos. Maio 2013. 49 pag. Disponível em:<https://www.christenseninstitute.org/publications/ensino-hibrido>. Acesso em: janeiro 2016.

DA ROCHA, A. M. Verbetes. In: Morosini, M. (ed.). Enciclopédia de Pedagogia Universitária: Glossário. Vol. 2. Brasília: INEP, 2006.

DA ROZA, M. P. Processos de aprendizagem e auto(trans)formação docente em Ambiente Digital Imersivo (ADI): convergência e novas coreografias no ensino superior. Projeto de Tese. PPGE/UFSM. 2017. 
FREIRE, P. Pedagogia da Autonomia: saberes necessários à prática educativa. São Paulo: Paz e terra, 1996.

. Pedagogia da Esperança: um reencontro com a pedagogia do oprimido. São Paulo: Paz e Terra, 1997.

FAGUNDES, L. da C., Valentini, C. B., Soares, E. M. do S. Linguagem, educação e recursos midiáticos: quem mexeu na minha escola? In: PESCADOR, Cristina Maria, SOARES, Eliana Maria do Sacramento, NODARI, Paulo César. Ética, educação e tecnologia: pensando alternativas para os desafios da educação na atualidade. Curitiba, PR: CRV, 2010.

GRAHAM, C. R. Blended learning systems: definition, current trends, and future directions. In: BONK, C.J.; GRAHAM, C. R.; CROSS, J.; MOORE. M.J. (eds.) The handbook of blended learning: global perspectives, local designs. São Francisco: Pfeiffer Publishing, 2006. 2 p. 30-41. Disponível em: http://www.publicationshare.com/graham_intro.pdf. Acesso em: dezembro 2016.

HENZ, C. I. Círculos Dialógicos Investigativo-Formativos e Auto(trans)formação Permanente de Professores. In Dialogus: Círculos Dialógicos, Humanização e auto(trans)formação de professores. São Leopoldo. Oikos. 2015.

LEVY, P. E Moraes, M.C. Informática Educativa no Brasil: uma história vivida e várias lições aprendidas. Revista Brasileira de Informática na Educação, Sociedade Brasileira de Informática na Educação, nº 1, pg. 19-44. 1997.

O'REILly, Tim. "What Is Web 2.0". O'Reilly Network. Disponível em: http://oreilly.com/web2/archive/what-is-web-20.html , acessado em maio de 2014.

PELLANDA, Nize Maria Campos. Maturana \& a Educação. Belo Horizonte: Autêntica Editora, 2009.

UNESCO. Padrões de competências em TIC para professores: marco político. 2009a. disponível em: <unesdoc.unesco.org/images/0015/001562/156210por.pdf>. Acesso em $15 / 05 / 2018$.

VALENTE, J. A. Um laptop para cada aluno: promessas e resultados educacionais efetivos. In: ALMEIDA, M. E. B. de; PRADO, M. E. B. B. O computador portátil na escola: mudanças e desafios nos processos de ensino e aprendizagem. São Paulo: Avercamp, 2011.

ZABALZA, M. A. (2006). Competencias docentes del profesorado universitario. Calidad y desarrollo profesional. Madrid-Es.: Narcea 